\title{
An Extended Cohesive Damage Model Study of Geometrical Ratio Effects on Failure Mechanisms of Functionally Graded Sandwiches with Multi-Layered Cores
}

\author{
S Ghimire and J Chen* \\ School of Civil Engineering and Surveying \\ University of Portsmouth, Portsmouth PO1 3AH, UK \\ *Corresponding address: jiye.chen@port.ac.uk
}

Key words: Functionally Graded Sandwiches Multi-layered core; Geometrical ratio effects; Extended Cohesive Damage Model; Predictive Shear Failure Modelling

\begin{abstract}
An investigation of geometrical ratio effects on failure mechanisms of functionally graded sandwiches with multi-layered cores (FGSMLC) is presented in this paper. The extended cohesive damage model (ECDM) is used in detailed investigations of geometrical ratio effects on the failure mechanisms of the FGSMLC under three-point bending. The ECDM prediction shows very good agreements with previous experimental work. The ECDM prediction reveals that the FGSMLC with 8-layered graded cores shows loading capacities increased by $64 \%$ compared to the one with a homogeneous core in all investigated cases with varied spans. The FGSMLC behaves different failure modes when their geometrical ratio between the depth and the span varies. It is the first time that this investigation explores the correlation between the failure load and the geometrical ratio of the FGSMLC. This investigation provides a sustainable approach to predict detailed failure mechanisms of the FGSMLC in further research and industrial applications.
\end{abstract}

\section{Introduction}

There are wide applications of composite sandwich panels in various industries such as automobile, aeronautical, civil, and others [1]. Composite sandwich panels are manufactured by attaching two thin layers of fibre laminates having very high material strength which are separated by a thick layer of core that is generally a material with lightweight and very low in material properties compared to top and bottom faces [1-3]. Fibre composite sandwiches show superior advantages [4] such as increased stiffness compared to other engineering materials [2]. There are other different benefits of using composite sandwich panels such as light weight, resistant to corrosive behaviour, high strength, high bending stiffness, etc. [2, 4, 5]. 
Usually honeycomb, corrugated, foam, and truss cores are used in composite sandwich panels. Core with honey comb and synthetic foam have been widely used in various application. For examples, various structures and parts in automotive industries, sporting industries and aerospace industries are built using core with honeycomb [6-8]. Likewise, synthetic foam based core have been used in panels for cladding [9], bridge decks [10, 11], various parts of ship [12], turbine blades [11] and flooring in building constructions [13]. However, this conventional sandwich panel is suffering from de-bonding or delamination at the interface between fiberlaminate on bottom and core due to high value of concentrated stresses and significantly varied material properties between the core and laminate at that region $[1,14]$, which restrains its loading capacity.

Some researches were carried out to mitigate those problems to reduce material property gap using functionally graded materials $[1,15,16]$. In their investigations different materials were mixed at different ratios to design a core with mixed materials, and the core is designed as a single layered core. On the other hand, composite sandwich panels by varying material properties on core were also investigated to reduce the gap between material properties by various researchers $[17,18]$. Material properties were varied non-uniformly that results in varied overall property on core. Strains in normal and shear directions were significantly decreased when core is functionally graded and discontinuities were reduced at the interface between the face sheets and the core, resulting in reduced deflection as well as stresses [17, 19].

Analytical, experimental and numerical modelling approaches were usually used to study the failure behaviour of composite sandwich panel in the past. In analytical approach, various theories based on the high order plate theory were used to calculate mechanical behaviour of composite sandwich panels having functionally graded cores (FGC). These analytical approaches employed third-order zig-zag model [20], 3-D elasticity equation [17], classical deflection formulae [21] and polynomial equation [19]. However, it was difficult to predict failure mechanisms of multi-layered composite sandwich panels in the structural level through these analytical approaches. Likewise, different experiment tests were carried out to investigate the failure mechanisms of FGC [18, 22]. Experimental tests were completed by [18] in examining the impact of variable densities of foam core to bending response on sandwich panels. There was a significant improvement on performance of a 4-layered sandwich panel having FGC on bending stiffness and resistance compared to traditional sandwich panels 
having homogeneous cores. However, experimental approach is costly in investigating failure mechanisms of the composite sandwich panel and optimizing its behaviour. On the other hand, the numerical modelling approach compared to other approaches is less time consuming and a cost-effective approach.

The geometrical ratio of composite sandwich panels will affect their failure behaviour. The effect of depth-span ratio on failure behaviour of aircraft sandwich panels under bending load was studied experimentally by [23] in which various spans such as $125 \mathrm{~mm}, 80 \mathrm{~mm}, 70 \mathrm{~mm}$ and $55 \mathrm{~mm}$ of honeycomb core sandwich panel were considered. Deflection was highly influenced by span length. Bending stiffness of the panel was decreased with increased span. Experimental results showed good agreements with analytical calculations calculated by [23] based on analytical formulation by [24]. Critical load is decreased but deflection is increased from short span to long span in honeycomb core sandwich panels. Effect of thickness was also investigated by [25] and concluded that increasing depth-to-span ratio will lead to increasing bending strength and bending stiffness. Failure mechanisms of composite sandwich panels with metal foam with varied densities were studied by [26] and found shear failure of foam core as major failure but this investigation was merely focused on a sample with one density and varied number of plies in faces. Likewise, impact of increasing thickness of faces has been studied by [27] and found improved stiffness, flexural rigidity and ultimate load. However, the effect of depth-span ratio of functionally graded sandwiches with multi-layered cores (FGSMLC) in which material properties are varied layer by layer in core were much less investigated in the past.

Cohesive zone model (CZM) [28, 29] and extended finite element method (XFEM) [30] are widely used to predict discontinuities in different structures for decades. In this paper, the failure behaviour of FGSMLC having various depth-span ratios are investigated using Extended Cohesive Damage Model (ECDM) considering its advantages in efficiency and accuracy comparted to CZM and XFEM [31-34]. This investigation is the first time to predict geometrical ratio effects on failure mechanisms of the FGSMLC. Experimental results from [18] are considered as reference in this paper. Detailed analysis of sandwich panel with varied geometrical ratio based on bending stiffness, failure load and residual stiffness are explored. The correlation between failure load and number of layers as well as depth-span ratio of the FGSMLC are explored by this investigation. 


\section{Methodology}

Prediction of failure mechanisms of the FGSMLC is one of the challenging issues in computational damage mechanics. Even though, CZM and XFEM are widely used to predict discontinuities in different structures for decades, however, these techniques have some drawbacks due to specific features of both techniques. CZM needs pre-defined crack paths and it also often faces convergent issues in simulation of crack propagation at the structural level simulation. Standard XFEM is a bit weak approach in simulating multicrack propagation in composites due to limited special functions given at the crack front. XFEM uses additional degrees of freedoms so computational burden is huge when dealing with strong discontinuities [31-34].

In this paper, the detailed failure mechanisms of the FGSMLC are studied using the highly efficient approach ECDM to predict non-linear failure mechanisms. The ECDM developed by Li and Chen [31-34] is capable to overcome the problems in CZM and XFEM. Reliability and validity of ECDM were identified through previous applications in simulating failure mechanisms in composites [31-34]. According to [31, 34], the computational efficiency of the ECDM is increased by $60 \%$ and $90 \%$ compared to XFEM and CZM respectively. Furthermore, the ECDM offers improved numerical accuracy and mesh independency. It was not found that convergent problems are encountered in non-linear failure analysis of investigated composite samples [31-34].

A user element model based on commercial package ABAQUS is used to apply ECDM in the non-linear failure analysis to investigate the geometrical ratio influence of the FGSMLC. Basic theoretical ECDM formulas that are implemented in an ECDM 2D 4-node quadrilateral element is described as below [31-34].

It is argued by [35] that partition of unity condition can be satisfied by a 2D quadrilateral 4node element with classical shape functions $N_{i}(i=1,2,3,4)$. Hence, the displacement approximation can be presented as shown in Eq. (1).

$$
\left\{\begin{array}{l}
u \\
v
\end{array}\right\}=\sum_{i=1}^{4} N_{i}(\xi, n)\left\{\begin{array}{l}
u_{i} \\
v_{i}
\end{array}\right\}+\sum_{i=1}^{4} \operatorname{step}_{i}(\xi, n) N_{i}(\xi, n)\left\{\begin{array}{l}
u_{i} \\
v_{i}
\end{array}\right\}
$$


Where, $u$ and $v$ are representing displacement in $\mathrm{x}$ and $\mathrm{y}$ directions respectively. And, step function can be expressed as:

$$
\operatorname{step}_{i}(\xi, n)=H_{\Gamma_{d}}(\xi, n)-H_{\Gamma_{d}}\left(\xi_{i}, n_{i}\right)
$$

According to [31-34] the shape function matrices $\mathbf{N}$ and the discretised gradient operator matrix $\mathbf{B}$ are established in general FEM format.

$$
[\mathbf{N}]=\left[\mathbf{N}_{\mathrm{STD}}, \mathbf{N}_{\mathrm{ENR}}\right]
$$

Where, standard function - $\mathbf{N}_{\mathrm{STD}}$ and enriched function - $\mathbf{N}_{\mathrm{ENR}}$ can be represented as:

$$
\begin{aligned}
& \mathbf{N}_{\mathrm{STD}}=\left[\begin{array}{cccccccc}
\mathrm{N}_{1} & \mathrm{O} & \mathrm{N}_{2} & \mathrm{O} & \mathrm{N}_{3} & \mathrm{O} & \mathrm{N}_{4} & \mathrm{O} \\
\mathrm{O} & \mathrm{N}_{1} & \mathrm{O} & \mathrm{N}_{2} & \mathrm{O} & \mathrm{N}_{3} & \mathrm{O} & \mathrm{N}_{4}
\end{array}\right] \\
& \mathbf{N}_{\text {ENR }}=\left[\begin{array}{cccccccc}
\text { step }_{1} N_{1} & 0 & \text { step }_{2} N_{2} & 0 & \text { step }_{3} N_{3} & 0 & \text { step }_{4} N_{4} & 0 \\
0 & \text { step }_{1} N_{1} & 0 & \text { step }_{2} N_{2} & 0 & \text { step }_{3} N_{3} & 0 & \text { step }_{4} N_{4}
\end{array}\right]
\end{aligned}
$$

According to [31-34], the formulation of ECDM is one-order lower order than that of XFEM, and only standard degrees of freedoms are used for nodal displacement in ECDM to represent discontinuities in cracked elements. Based on the weak form of equilibrium equation by Bubnov-Galerkin method, the discrete form of final equilibrium equation for static analysis can be represented as:

$$
\left(\mathbf{K}^{u u}-\mathbf{K}^{u a}\left(\mathbf{K}^{a a}\right)^{-1} \mathbf{K}^{a u}\right) u=\mathbf{f}_{e x t}^{u}-\mathbf{K}^{u a}\left(\mathbf{K}^{a a}\right)^{-1} \mathbf{f}_{c o h}
$$

Where, $\mathbf{u}$ represents displacement due to standard degrees of freedom, matrices $\mathbf{K}^{\mathrm{uu}}$ and $\mathbf{K}^{\mathrm{aa}}$ are representing standard and enriched approximation respectively. Likewise, $\mathbf{K}^{\mathrm{ua}}$ and $\mathbf{K}^{\mathrm{au}}$ are representing coupled standard and enriched FE approximations; $\mathbf{f}_{\text {ext }}^{u}$ is for equivalent nodal force vector due to standard FEM degrees of freedom. Calculations for $\mathbf{K}^{\mathrm{uu}}, \mathbf{K}^{\mathrm{aa}}, \mathbf{K}^{\mathrm{ua}}$ and $\mathbf{K}^{\mathrm{au}}$ are given as below. 


$$
\begin{aligned}
\mathbf{K}^{\mathrm{uu}} & =\int_{\Omega_{\mathrm{e}}^{+}} \mathbf{B}_{\mathrm{STD}} \mathbf{D B}_{\mathrm{STD}} \mathrm{d} \Omega+\int_{\Omega_{\mathrm{e}}^{-}} \mathbf{B}_{\mathrm{STD}} \mathbf{D} \mathbf{B}_{\mathrm{STD}} \mathrm{d} \Omega \\
\mathbf{K}^{\mathrm{au}} & =\int_{\Omega_{\mathrm{e}}^{+}} \mathbf{B}_{\mathrm{ENR}} \mathbf{D} \mathbf{B}_{\mathrm{STD}} \mathrm{d} \Omega+\int_{\Omega_{\mathrm{e}}^{-}} \mathbf{B}_{\mathrm{ENR}} \mathbf{D} \mathbf{B}_{\mathrm{STD}} \mathrm{d} \Omega \\
\mathbf{K}^{\mathrm{ua}} & =\int_{\Omega_{\mathrm{e}}^{+}} \mathbf{B}_{\mathrm{STD}} \mathbf{D} \mathbf{B}_{\mathrm{ENR}} \mathrm{d} \Omega+\int_{\Omega_{\mathrm{e}}^{-}} \mathbf{B}_{\mathrm{STD}} \mathbf{D} \mathbf{B}_{\mathrm{ENR}} \mathrm{d} \Omega \\
\mathbf{K}^{\mathrm{aa}} & =\int_{\Omega_{\mathrm{e}}^{+}} \mathbf{B}_{\mathrm{ENR}} \mathbf{D} \mathbf{B}_{\mathrm{ENR}} \mathrm{d} \Omega+\int_{\Omega_{\mathrm{e}}^{-}} \mathbf{B}_{\mathrm{ENR}} \mathbf{D} \mathbf{B}_{\mathrm{ENR}} \mathrm{d} \Omega
\end{aligned}
$$

Where, the gradient matrices $\mathbf{B}$ for 2D quadrilateral element can be expressed as:

$$
[\mathbf{B}]=\left[\mathbf{B}_{\mathrm{STD}}, \mathbf{B}_{\mathrm{ENR}}\right]
$$

Where, $\mathbf{B}_{\mathrm{STD}}$ and $\mathbf{B}_{\mathrm{ENR}}$ can be calculated by Equs. 9 and 10 .

$$
\begin{gathered}
\mathbf{B}_{\mathrm{STD}}=\left[\begin{array}{cc}
N_{i, x} & 0 \\
0 & N_{i, y} \\
N_{i, y} & N_{i, x}
\end{array}\right] \\
\mathbf{B}_{\mathrm{ENR}}=\left[\begin{array}{cc}
\operatorname{step}_{\mathrm{i}} \mathrm{N}_{\mathrm{i}, \mathrm{x}}+\operatorname{step}_{\mathrm{i}, \mathrm{x}} \mathrm{N}_{\mathrm{i}} & 0 \\
\operatorname{step}_{\mathrm{i}} \mathrm{N}_{\mathrm{i}, \mathrm{y}}+\operatorname{step}_{\mathrm{i}, \mathrm{y}} \mathrm{N}_{\mathrm{i}} & \mathrm{s}_{\mathrm{i}, \mathrm{y}}+\operatorname{step}_{\mathrm{i}, \mathrm{y}} \mathrm{N}_{\mathrm{i}} \operatorname{step}_{\mathrm{i}} \mathrm{N}_{\mathrm{i}, \mathrm{x}}+\operatorname{step}_{\mathrm{i}, \mathrm{x}} \mathrm{N}_{\mathrm{i}}
\end{array}\right]
\end{gathered}
$$

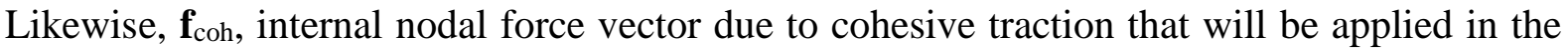
crack surface as shown in Fig. 1, can be expressed by Equ. 11.

$$
\mathbf{f}_{\text {coh }}=\int_{\Gamma_{\text {Element }}^{\text {Crack }}} \mathbf{N}_{\mathrm{STD}} \mathbf{t} d \Gamma
$$

In which, $\mathbf{t}$ represents traction between two crack surfaces on a cracked element.

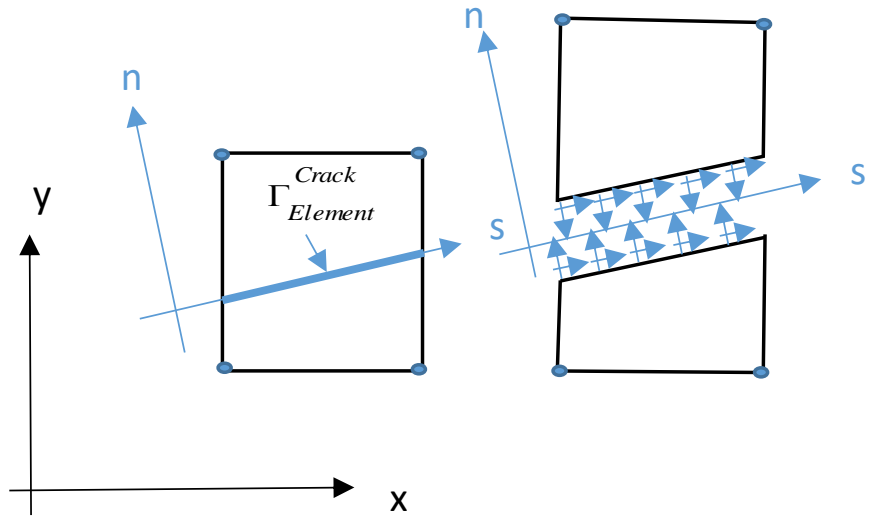


Fig. 1: Cohesive tractions between cracked surfaces

In this investigation, a mixed-mode failure criterion is considered. Total fracture energy is considered as a function of crack mode ratio by Benzeggagh and Kenane also known as B-K law for mixed-mode failure. According to Reeder [36], the following expression can be used as 3D mixed mode failure criteria:

$$
\frac{G_{T}}{G_{I C}+\left(\left(G_{I I C}-G_{I C}\right)\left(G_{I I} / G_{T}\right)+\left(G_{I I C}-G_{I C}\right)\left(G_{I I I} / G_{T}\right)\right)\left(\left(G_{I I}+G_{I I I}\right) / G_{T}\right)^{n-1}} \geq 1
$$

Where, $G_{T}$ is total energy release rate which is equivalent to $G_{I}+G_{I I}+G_{I I I}$ and accounted as a function of the ratio $\left(\mathrm{G}_{I I}+G_{I I I}\right) / \mathrm{G}_{\mathrm{T}}$. Likewise, $G_{I C}, G_{I I C}$ and $G_{I I I C}$ are opening and two shear fracture energies respectively, $\mathrm{n}$ is the power faction parameter.

In $2 \mathrm{D}$ case $G_{I I I}=0$, so, it is equivalent to B-K criteria [37] as given in Equ. 13 for 2D cases:

$$
\frac{G_{T}}{G_{I C}+\left(G_{I I C}-G_{I C}\right)\left(G_{I I} / G_{T}\right)^{n}} \geq 1
$$

\section{Geometry and material property of sandwich samples}

The main theme of this research is to investigate the detailed failure mechanisms of FGSMLC with varied material properties layer by layer and explore the correlation between failure load and geometrical ratio. An initial sample as a three point bending test from [18] is considered in this investigation. The sandwich sample with dimensions of $90 \mathrm{~mm}$ span L, $20 \mathrm{~mm}$ width B and $12 \mathrm{~mm}$ depth $\mathrm{H}$ was manufactured by glued fibre laminates and foam as shown in Figs. 2 and 3. The FGSMLC panels having 10 different span cases ranged from $15 \mathrm{~mm}$ to $100 \mathrm{~mm}$, a fixed width of $20 \mathrm{~mm}$ and total thickness or depth of $12 \mathrm{~mm}$ are investigated. A 2D half model with $8 \mathrm{~mm}$ thick core and $2 \mathrm{~mm}$ thick top and bottom laminates taking benefit of symmetric case is considered. Simply supported supporting conditions at two edges align with three-point bending test and displacement controlled loading scheme by a loading cell at the middle of sandwich panel as shown in Fig. 4 are used. An ECDM based 2D plain strain elements are applied in modelling.

Top and bottom laminates are manufactured by twelve woven bi-directional layers of carbon fibre-T300 and homogeneous foam core is manufactured by $3 \mathrm{M}^{\mathrm{TM}}$ using $\mathrm{K} 20$ hollow glass 
microspheres with binder resin epoxy 520 and 523 hardener [18]. Their material properties are given in Tables 1 and 2. Foam core material properties are comparatively higher than what in ordinary foam materials.

Table 1: Basic material properties for top and bottom laminates

\begin{tabular}{|c|c|c|c|c|c|c|c|c|}
\hline \multicolumn{3}{|c|}{$\begin{array}{c}\text { Young's moduli } \\
\text { (MPa) }\end{array}$} & \multicolumn{3}{c|}{$\begin{array}{c}\text { Shear moduli } \\
\text { (MPa) }\end{array}$} & \multicolumn{3}{c|}{ Poisson ratio } \\
\hline $\mathrm{E}_{1}$ & $\mathrm{E}_{2}$ & $\mathrm{E}_{3}$ & $\mathrm{G}_{12}$ & $\mathrm{G}_{13}$ & $\mathrm{G}_{23}$ & $\mathrm{~V}_{12}$ & $\mathrm{~V}_{13}$ & $\mathrm{~V}_{23}$ \\
\hline 35000 & 35000 & 3150 & 13257 & 13257 & 13257 & 0.33 & 0.33 & 0.33 \\
\hline
\end{tabular}

Table 2: Foam material properties of homogeneous core

\begin{tabular}{|c|c|c|c|c|}
\hline $\begin{array}{c}\text { Young's modulus } \\
(\mathrm{MPa})\end{array}$ & $\begin{array}{c}\text { Poisson } \\
\text { ratio }\end{array}$ & $\begin{array}{c}\text { Normal strength } \\
(\mathrm{MPa})\end{array}$ & $\begin{array}{c}\text { Shear Strength } \\
(\mathrm{MPa})\end{array}$ & Fracture Energy (N/mm) \\
\hline 1500 & 0.35 & 26.25 & 9.865 & 0.32 \\
\hline
\end{tabular}

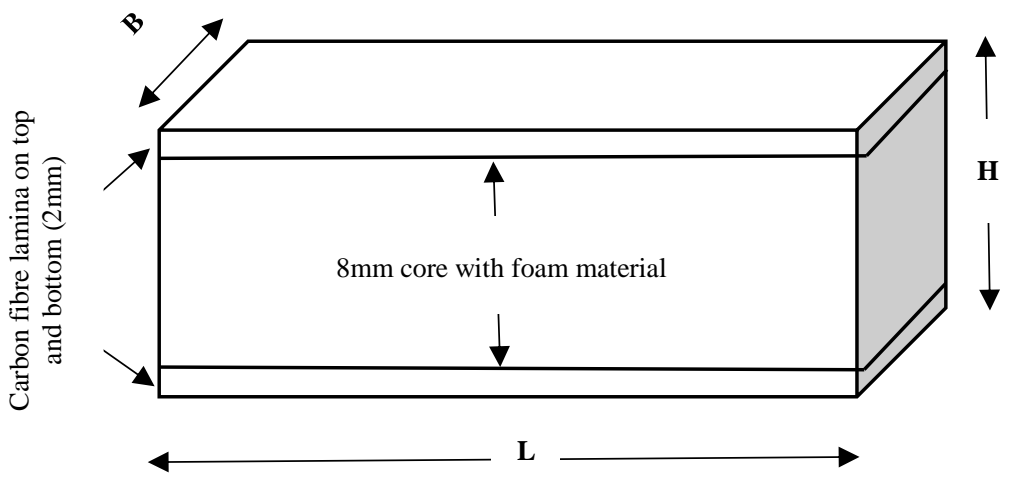

Fig. 2: A sandwich panel with a homogeneous core (not to scale)

\section{Results analysis and discussion}

Results analysis and discussion are given in the following three sections. Firstly, the ECDM modelling work is conducted for comparing with experimental results given in [18] for verifying the ECDM prediction. Secondly, geometrical ratio effects on failure mechanisms of FGSMLC with various spans are studied. Finally, the correlation between failure load and depth-span geometrical ratio is explored.

\subsection{Verification of ECDM predictions}

This section presents two different simulations: the first one with homogeneous foam core and second one with 4-layered functionally graded core. Table 3 shows the material properties of 4-layered core sandwich panels. Material properties of homogeneous core are same as the material properties for layers 2 and 3 in Table 3. 


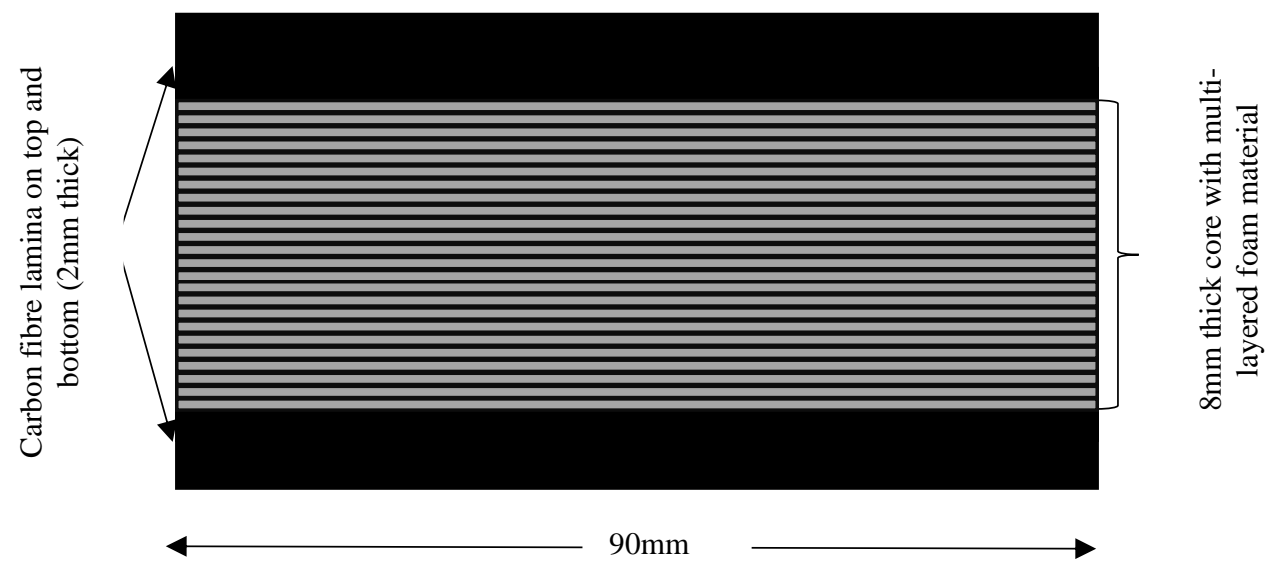

Fig. 3: A cross-sectional view of sandwich panel with a multi-layered core (not to scale)

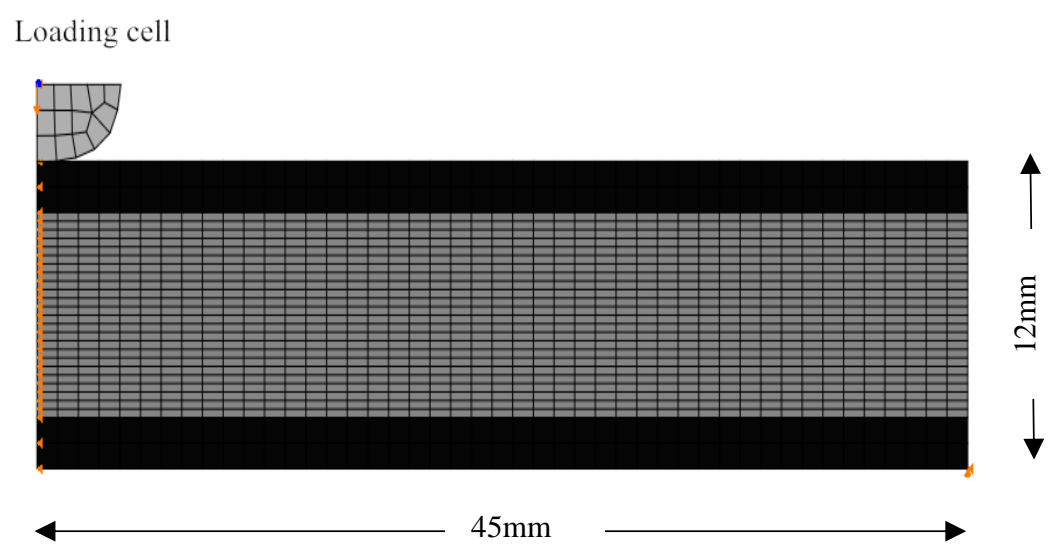

Fig. 4: A half model of sandwich panel

Table 3: material properties of sandwich panel with 4-layered core

\begin{tabular}{|c|c|c|c|c|c|}
\hline Layer & $\begin{array}{c}\text { Young's } \\
\text { modulus (MPa) }\end{array}$ & Poisson ratio & $\begin{array}{c}\text { Normal strength } \\
(\mathrm{MPa})\end{array}$ & $\begin{array}{c}\text { Shear strength } \\
(\mathrm{MPa})\end{array}$ & $\begin{array}{c}\text { Fracture energy } \\
(\mathrm{N} / \mathrm{mm})\end{array}$ \\
\hline 1 & 1900 & 0.36 & 33.25 & 12.495 & 0.41 \\
\hline 2 & 1500 & 0.35 & 26.25 & 9.865 & 0.32 \\
\hline 3 & 1500 & 0.35 & 26.25 & 9.865 & 0.32 \\
\hline 4 & 1900 & 0.36 & 33.25 & 12.495 & 0.41 \\
\hline
\end{tabular}

Figs. 5 and 6 shows the failure modes given by experimental test and ECDM prediction respectively. There is a good agreement between the ECDM prediction and experimental test. Fig. 5 shows experimentally presented dominated sliding shear cracks from the edge to the middle of the panel followed by the main through thickness cracks at the middle of the panel. While, as presented in Fig. 6, grey colour is representing sliding shear cracks or delamination initiated at the edge and propagated to the middle of the panel, which is in the line of the tested failure mode. Fig. 6 also shows the direction of through thickness crack growth at the middle, which agrees with test observation in the middle area. The failure mode is sliding shear crack 
starts from the edge of the panel due to concentrated shear stresses, then cracks propagate towards the middle of the panel as fracture energy released. Along the main sliding shear cracking path a few through thickness cracks are captured by both experimental test and ECDM prediction as shown in Figs. 5 and 6 respectively. Furthermore, a mixed failure mode with tensile and shear failure is occurred in the middle area of the panel due to high values of shear stresses as well as tensile stresses. It is noticed that sliding shear cack or delamination slightly above the interface between the core and the bottom sheet captured by both experimental test and ECDM prediction. This is because high values of stresses in that region above the interface due to materials mismatch.

The failure mode of the sandwich panel with 4-layered core was not presented by [18]. The ECDM predicted its failure mode can be seen from Fig. 7, which is similar to that in the case of homogenous core. It is dominated by sliding shear failure from the edge to the middle of the panel, however, there are more through thickness cracks along the sliding cracking path. Cracked surfaces are expanded in the sandwich panel with 4-layered core. It can be seen from Fig. 8 that initial stiffness and failure load have very good agreements between experimental tests and ECDM predictions in both homogeneous and 4-layered cases. Results revealed that loading capacity of sandwich panel with 4-layered core compared to homogeneous core has improved by $26 \%$ in ECDM prediction and $22 \%$ in experimental observations.

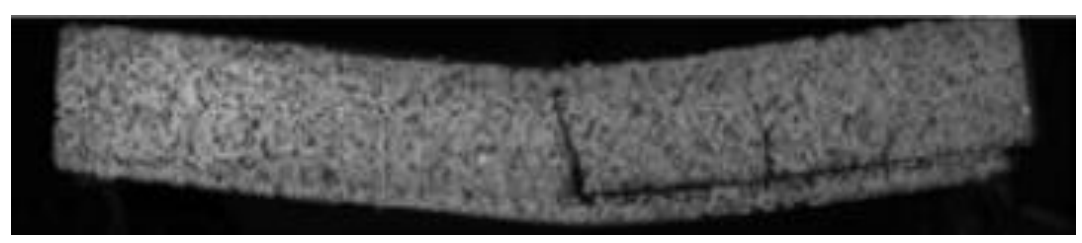

Fig 5: Experimentally tested sandwich panel with a homogenous core [18]

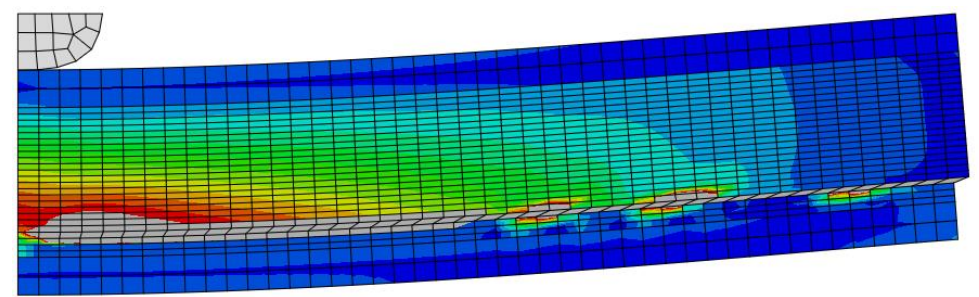

Fig. 6: ECDM predicted failure mode of sandwich panel with a homogenous core 


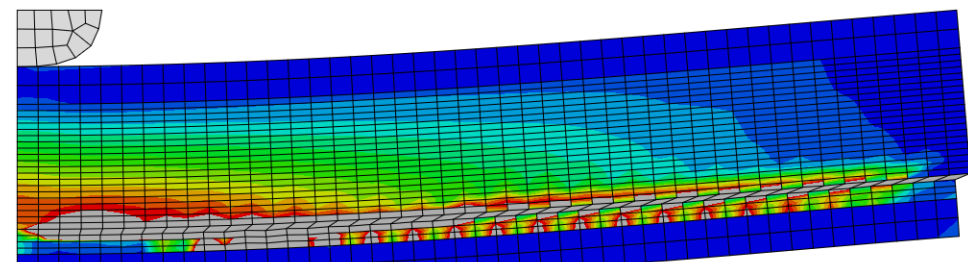

Fig. 7: ECDM predicted failure mode of sandwich panel with a 4-layered core

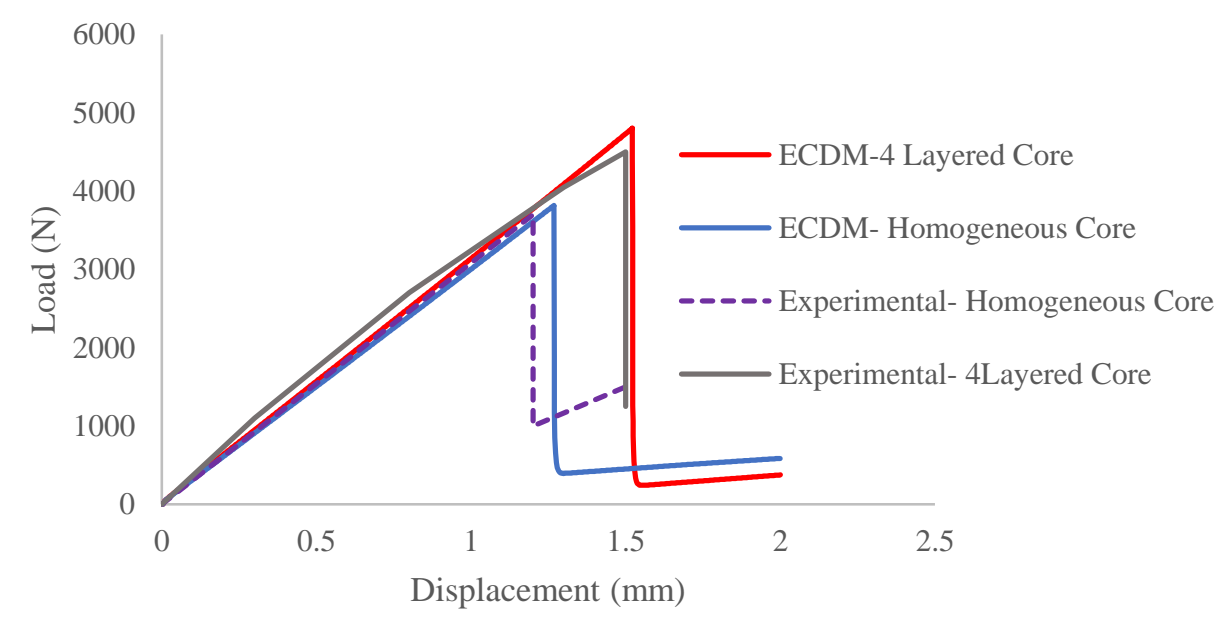

Fig. 8: ECDM predicted failure responses and experimental solutions [18]

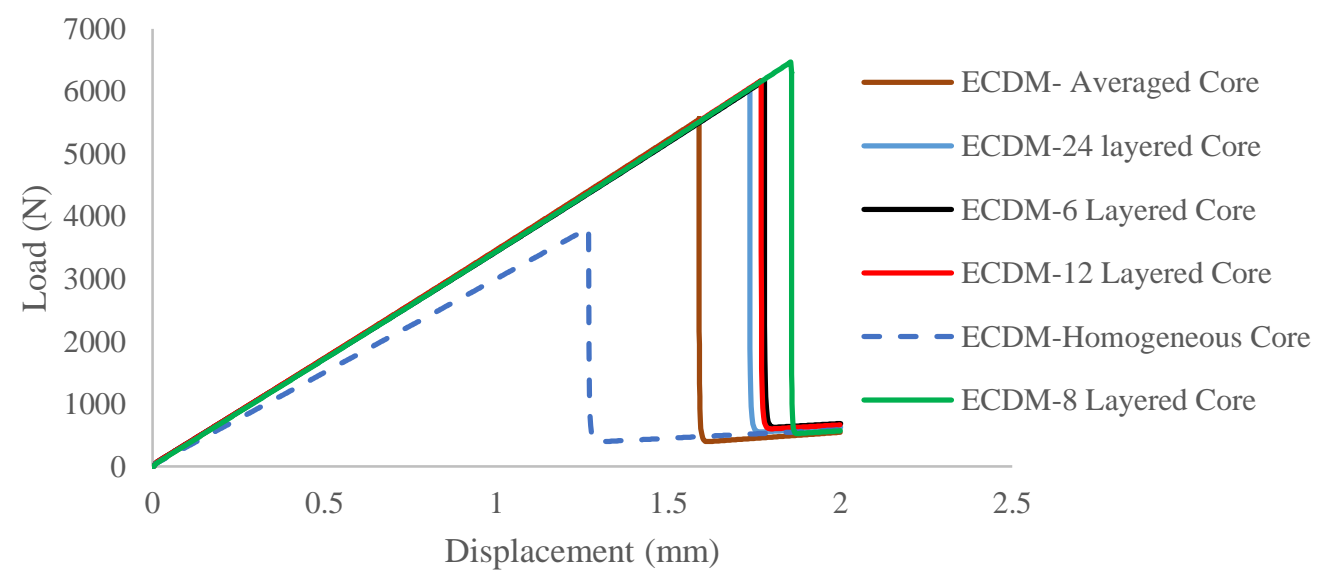

Fig. 9: ECDM predicted failure responses for three different core cases

Furthermore, the ECDM investigations are carried out for multi-layered core where material properties are increased proportionally layer by layer up to $100 \%$ from the middle of the sandwich panel towards top and bottom sheets to decrease the material gap between the core and the laminated sheets. The case of the core with average material properties is also 
investigated based on the $90 \mathrm{~mm}$ span model for comparison. It is noted that original homogeneous core material properties are as tabulated in Table 2 and the averaged material properties are derived by taking the average between the original homogeneous material properties and the $100 \%$ increment. It can be seen from Fig. 9 that the case with 8-layered core perform the best with highest failure load. Loading capacity of 8-layered core is increased by $64 \%$ and $13 \%$ compared to original homogeneous and averaged homogeneous core.

\subsection{Geometrical ratio effect of the sandwiches with multi-layered cores}

The ECDM prediction has been verified by the comparative study carried out in section 4.1. In this section, further investigations based on ECDM are carried out by varying depth-span ratio from 0.12 to 0.8 . The depth of sandwich panel is kept as a constant as $12 \mathrm{~mm}$ and span is varied from $15 \mathrm{~mm}$ to $100 \mathrm{~mm}$. Geometrical depth-span ratio effect are investigated through fifty different simulations for homogeneous, 6, 8, 12, and 24 layered cores with various spans. As presented and discussed in previous section, failure load in 8 layered core is significantly increased compared to homogeneous core. It is happened in the most variable span cases, so, failure responses of selected two cases; homogeneous core and 8 layered core, are discussed in details for comparison.

Figs. 10 and 11 show the failure responses of homogeneous core and 8 layered core with various spans predicted by ECDM. It can be seen from Figs. 10 and 11 that failure responses of sandwich panels with homogeneous and 8 layered cores have a similar load-displacement curve in all span cases. Failure responses of long span cases have a single failure point, on the other hand, failure responses of short span cases have multiple failure points. It is noted that initial stiffness of sandwich panel is increased when span decreased in all investigated cases. Similar behaviours can be seen in other investigated cases with variable number of layers e.g. 6,12 , and 24. A similar behaviour is appeared in all shorter span cases having less $30 \mathrm{~mm}$ span length. Hence, the first case for short spans representing the cases where initial failure is caused by through-thickness shear failure and having higher residual stiffness represented by $20 \mathrm{~mm}$ span is considered for detailed analysis. Likewise, longer spans having $40 \mathrm{~mm}$ or more also behave a similar failure mode, therefore, the second case with $40 \mathrm{~mm}$ span representing all other long spans having only one major horizontal sliding shear failure is discussed in details.

As shown in Figs. 12 and 13, the failure modes are basically dominated by one sliding shear failure presented by grey colour, which occurs when geometrical ratio is 0.3 or less regarding 
medium to long span cases. Sandwich panel loses its loading capacity as the shear failed areas completely cracked through the whole panel. There is some extent of residual stiffness because split parts by shear failure are still contacted from each other.

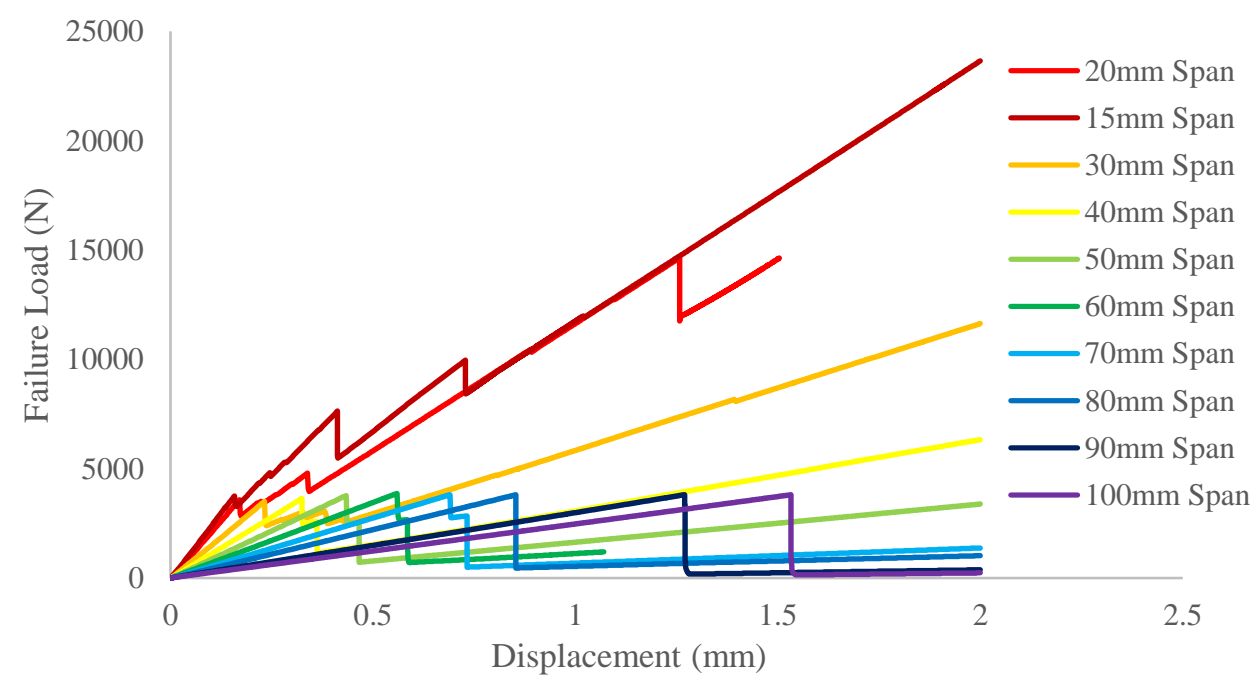

Fig. 10: Failure responses of homogeneous core with various spans

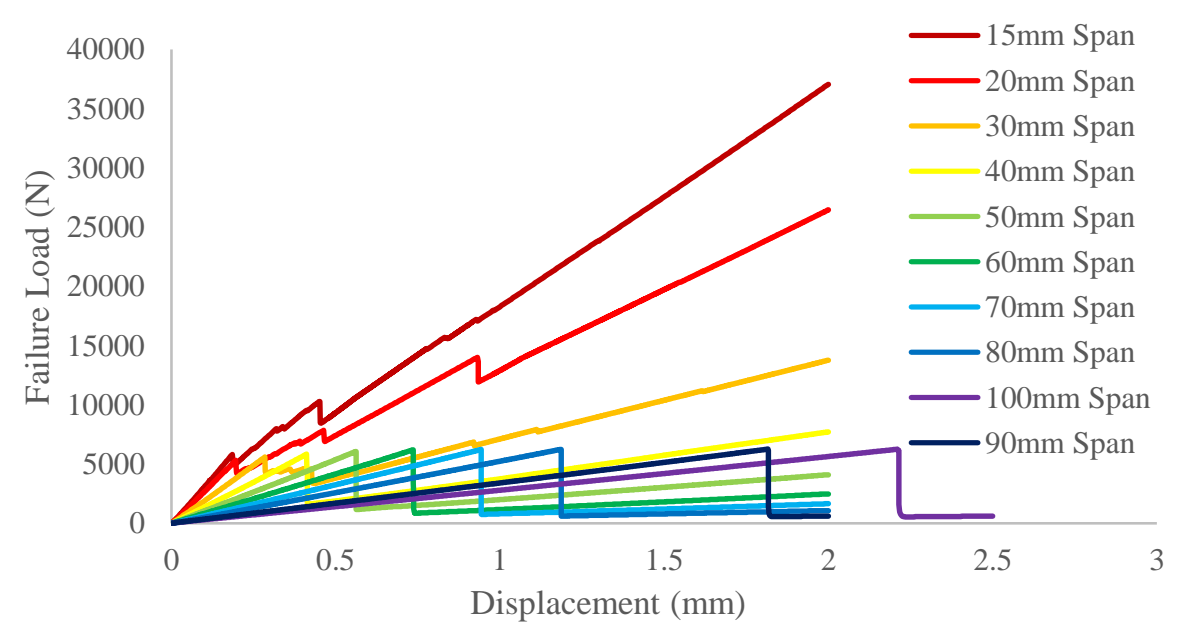

Fig. 11: Failure responses of 8 layered core with various spans 


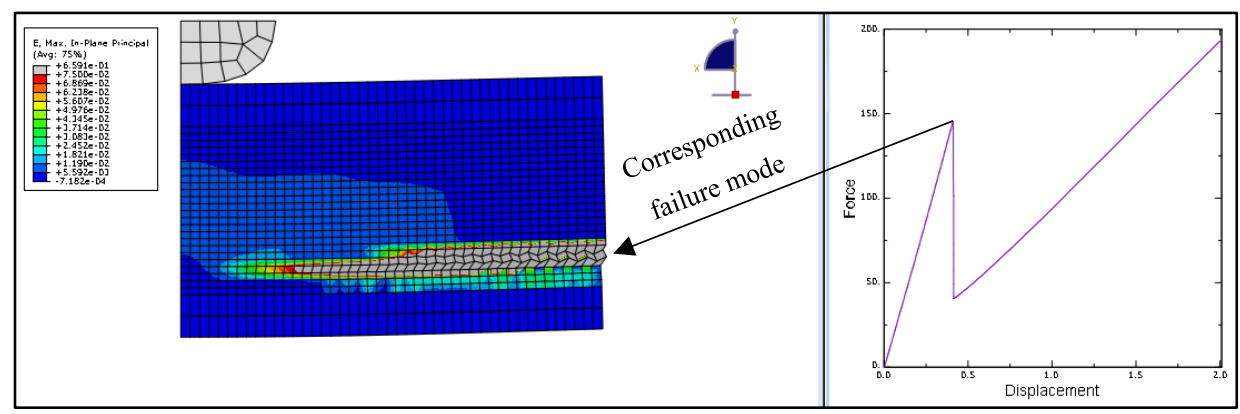

Fig. 12: Failure mode at the first failure point of $40 \mathrm{~mm}$ span case with 8 layered core

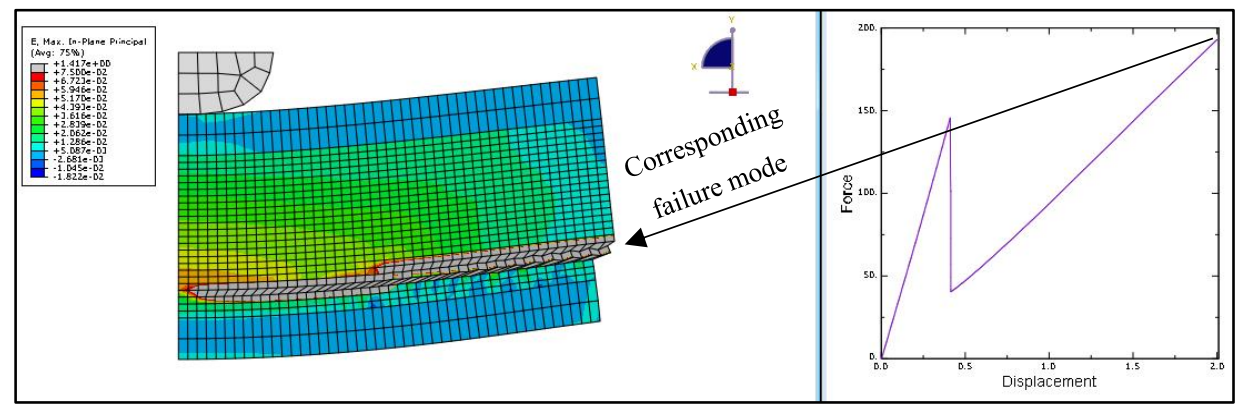

Fig. 13: Failure mode at the final stage of $40 \mathrm{~mm}$ span case with 8 layered core

At the transition stage e.g. geometrical ratio between 0.3 to 0.4 or medium span stage, the failure load of the FGSMLC is slightly decreased. This is because initial failure mode changes as shown in Fig. 14 when ratio is 0.4 from sliding shear failure to through-thickness shear failure at the beginning of failure in which strain energy distribution is slightly changed. It is followed by sliding shear failure which consists of a number of through-thickness cracks. Fig. 15 and 16 show the failure mode at the second and third failure points respectively in the loaddisplacement curve, which is continued sliding shear failure from the edge to the middle of the panel. Fig. 17 shows the failure mode at the final stage in the load-displacement curve, which shows two sliding shear cracks almost reached the middle of the panel at the final stage. The additional sliding shear crack is appeared exactly at the interface between the core and bottom sheet. 


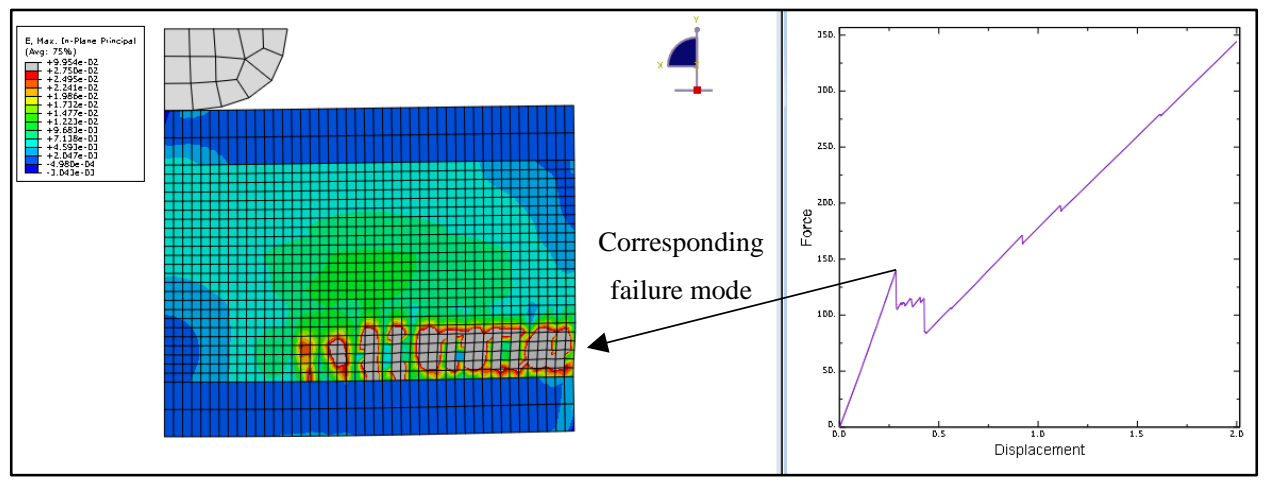

Fig.14: Failure mode at the first failure point of $30 \mathrm{~mm}$ span case with 8 layered core

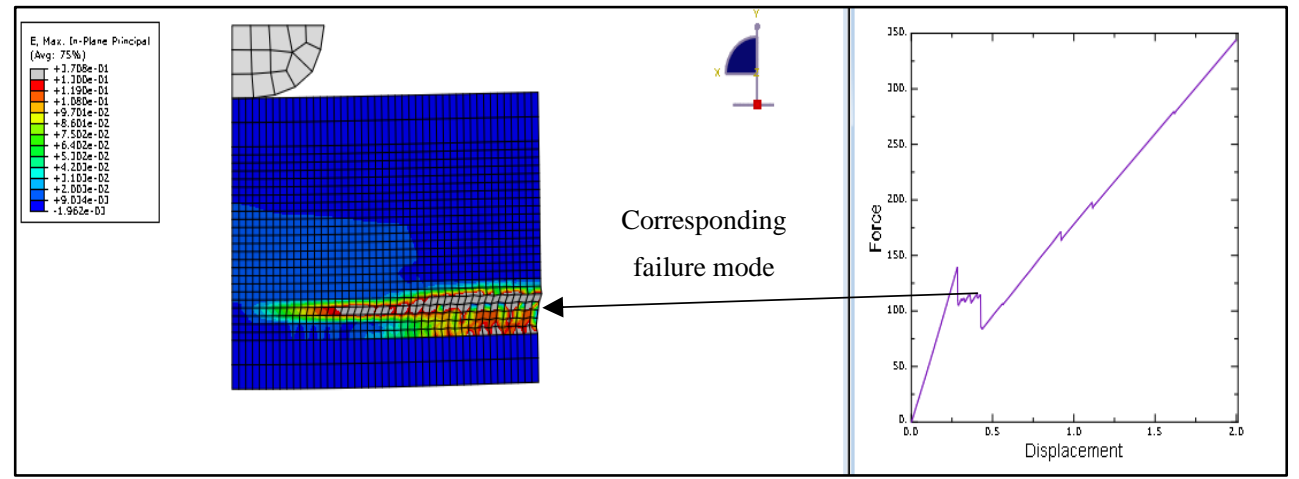

Fig. 15: Failure mode at the second failure point of $30 \mathrm{~mm}$ span case with 8 layered core

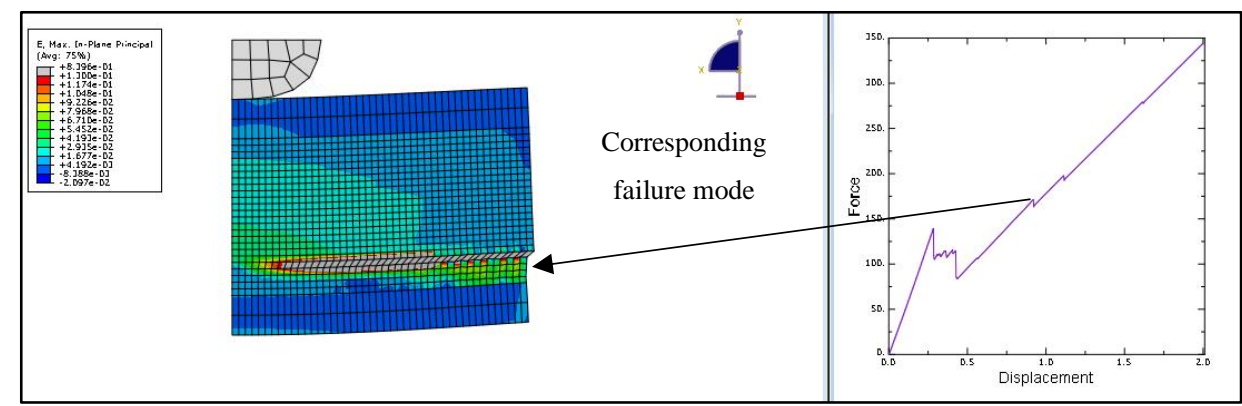

Fig. 16: Failure mode at the third failure point of $30 \mathrm{~mm}$ span case with 8 layered core 


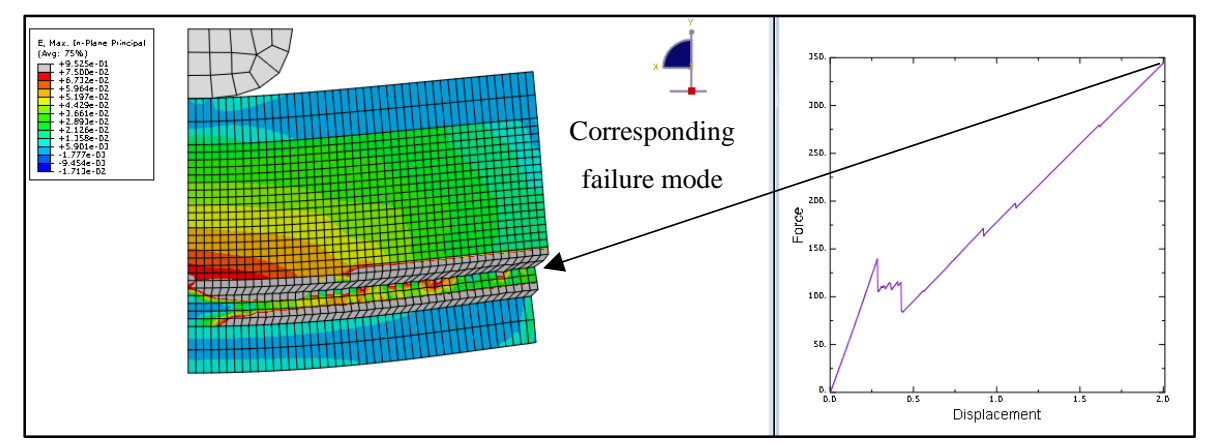

Fig. 17: Failure mode at the final stage of $30 \mathrm{~mm}$ span case with 8 layered core

Figs. 18 to 21 show the failure modes of the panel with $20 \mathrm{~mm}$ span or geometrical ratio 0.6 and an 8 layered core, which has three failure points in the load-displacement curve. The failure starts from a number of individual through-thickness cracks at the first failure point in the loaddisplacement curve as shown in Fig. 18. It links individual through-thickness cracks together as a continued sliding shear crack at the second failure point as shown in Fig. 19. At the third failure point, one more sliding shear failure crack is appeared at the interface between the core and the bottom sheet as shown in Fig. 20. Fig. 21 shows two sliding shear cracks almost reached the middle of the panel at the final stage.

In the cases of high geometrical ratio such as above 0.6, failure always initiates from the edge towards the middle of the panel, and failure modes distributed in several layers in throughthickness way. They are multiple failure modes including individual through-thickness cracks at the beginning and the following multiple sliding shear cracks in different levels. The more number of layers and the bigger failed area are associated with the final or major failure mode. Hence, it needs high fracture energy to split the panel and results in increased failure loads.

\subsection{Correlation between failure load and geometrical ratio}

Detailed failure mechanisms of the FGSMLC with various spans is analysed in previous sections. In this section, detailed effects of geometrical ratio on failure mechanisms is explored. Fig. 22 shows the correlation between geometrical depth-span ratio and failure load of the FGSMLC. The FGSMLC with homogeneous core, 6, 8, 12 and 24-layer cores are considered in this investigation. 


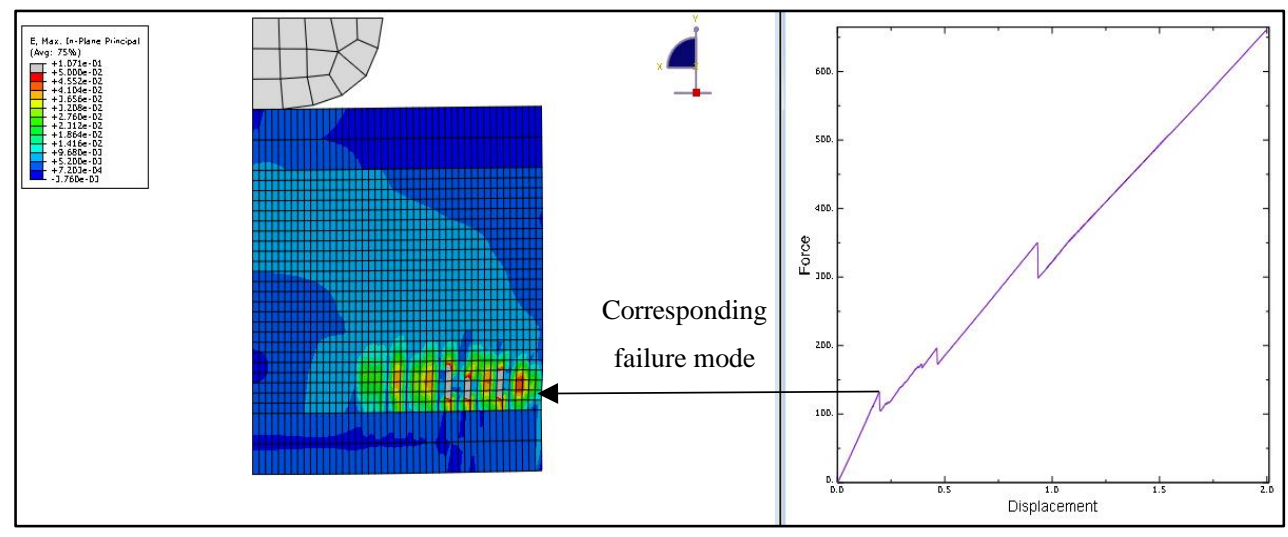

Fig. 18: Failure mode at the first failure point of $20 \mathrm{~mm}$ span case with 8 layered core

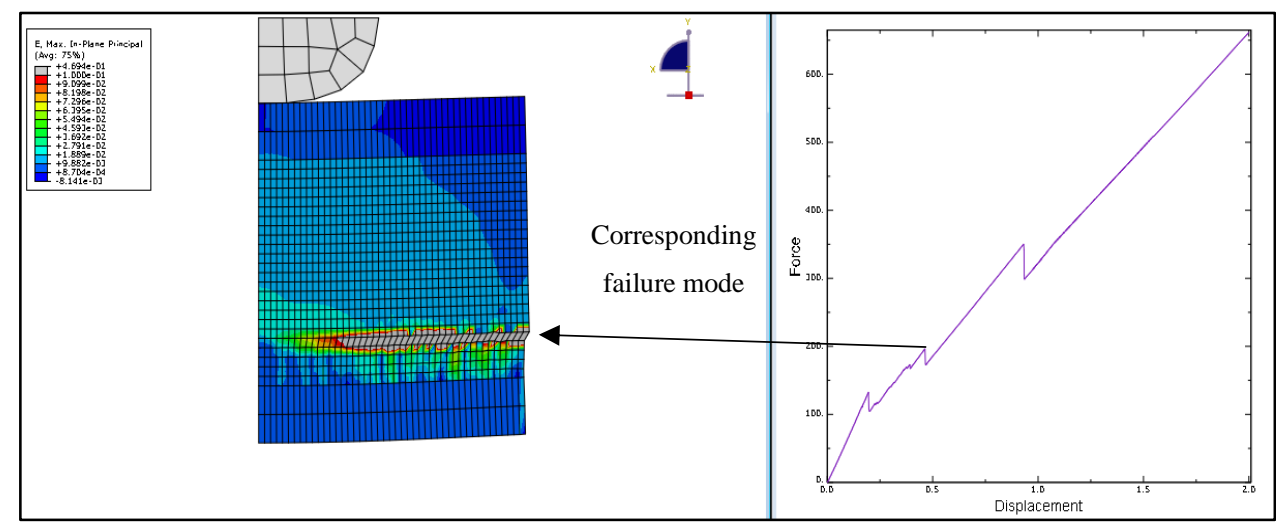

Fig. 19: Failure mode at the second failure point of $20 \mathrm{~mm}$ span case with 8 layered core

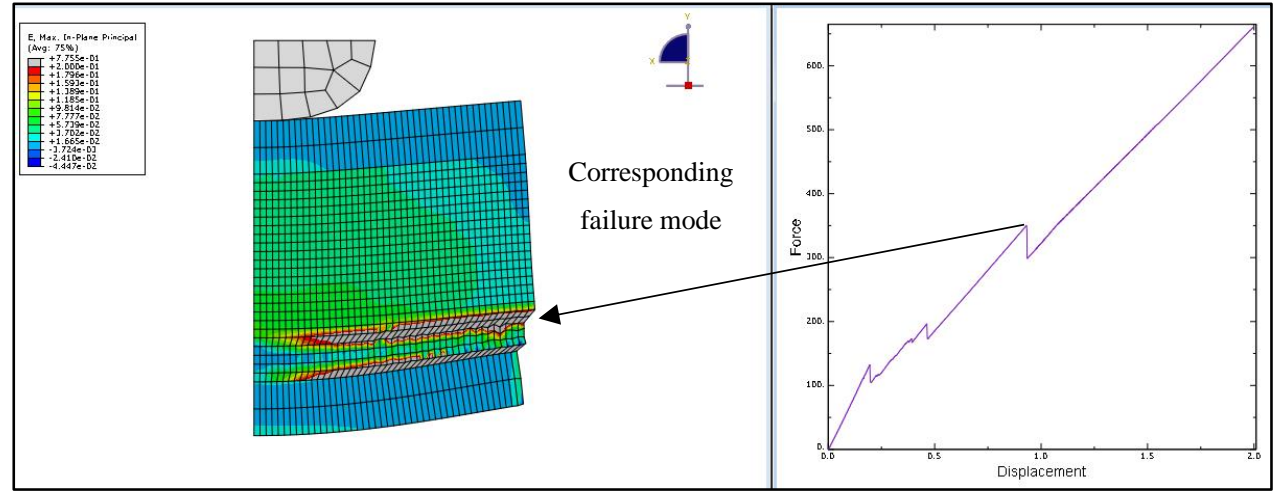

Fig. 20: Failure mode at the third failure point of $20 \mathrm{~mm}$ span case with 8 layered core 


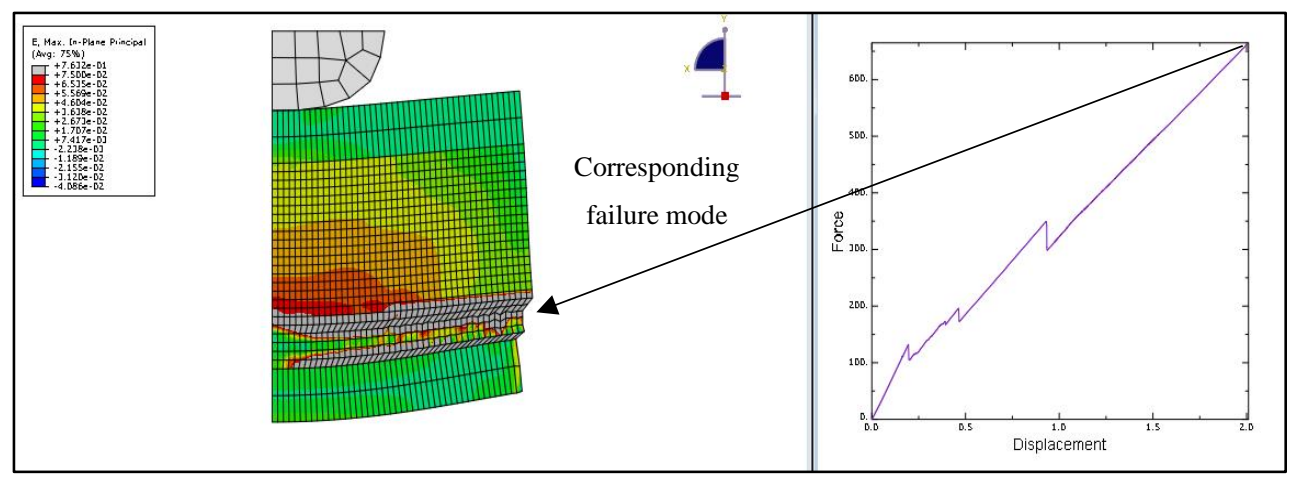

Fig. 21: Failure mode at the final stage of $20 \mathrm{~mm}$ span case with 8 layered core

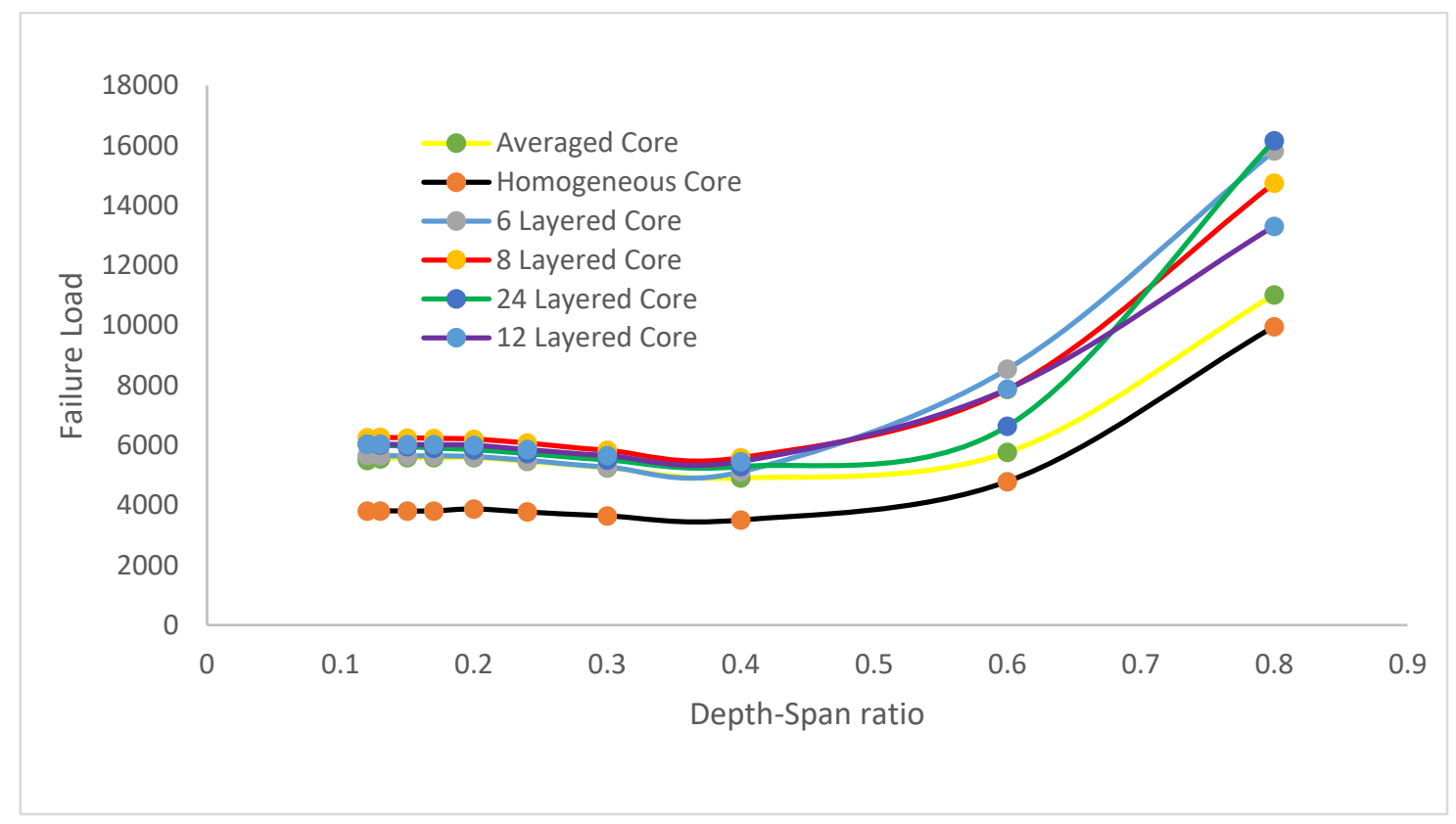

Fig. 22: Correlation between failure load and geometrical depth-span ratio

Fig. 22 shows the correlation between the geometrical ratio and failure load of the FGSMLC. Results from this investigation reveal that the performance of the FGSMLC is varied when depth-span ratio is varied from 0.12 to 0.8 or long span to short span. Failure load is relatively a constant when geometrical ratio is in between 0.12 and 0.3 in the long span cases. It is slightly decreased when geometrical ratio varies from 0.3 to 0.4 in the medium span cases. However, failure load is drastically increased when geometrical ratio is over 0.4 in the short span cases. It can be seen from Fig. 22 that the FGSMLC shows varied behaviours as geometrical ratio varies and anisotropic natures of sandwich panels. 
In the long span cases or geometrical ratio less than 0.3 , the failure mode is always horizontal sliding shear crack from the beginning to the end. A mixed failure mode with through-thickness shear and horizontal sliding shear cracks occurs at the initial failure stage when geometrical ratio is over 0.4 regarding short span cases. It is noticed that there is a transition between horizontal sliding shear failure and through-thickness shear failure in the medium span cases or geometrical ratio between 0.3 and 0.4. In all short span cases, through-thickness shear cracks initiate first then followed by horizontal sliding shear cracks. However, the final or major failure mode is dominated by multiple layered sliding shear cracks, and each layered sliding failure consists of through-thickness shear cracks at different points along the span direction. This mixed failure mode requires high strain energy to crack the panel in both span and throughthickness directions, which leads a drastically increased failure load.

It is also revealed that the loading capacity varies when the number of layer of the core varies. In the medium and long span cases e.g. geometrical ratio is in between 0.12 and 0.4 , the number of layers of the core has influence in some extent, the case with 8 layered core shows a higher failure load than others. In average, the loading capacities of the FGSMLC with 8-layered core are increased by $64 \%$ and $12 \%$ compared to the cases with original homogeneous and averaged homogeneous cores respectively in the medium to long span cases. In the short span cases, the number of layers of the core shows more influence. The case with 6 layered core shows superior loading capacity when ratio is between 0.5 and 0.75 . Failure load of the case with 6-layered core is increased by $78 \%$ and $48 \%$ compared to the cases with original homogeneous and averaged homogeneous cores respectively when geometrical ratio is 0.6. However, the case of 24 layered core shows the maximum failure load when geometrical ratio is 0.8 and a trend of increasing failure load as increasing geometrical ratio. The loading capacity of the FGSMLC with 24-layered core is increased by $62 \%$ and $46 \%$ compared to the cases with original homogeneous and averaged homogeneous cores respectively when geometrical ratio is 0.8 .

\section{Conclusions and the future work}

The geometrical ratio effect on the failure mechanisms of the FGSMLC was successfully investigated in this paper using ECDM. There are good agreements between ECDM predictions and previous experimental work on failure mechanisms of composite sandwich panel with homogeneous core and 4-layered core. Loading capacity is significantly improved with multilayered core. In average, loading capacities of the FGSMLC with a 8-layered core are increased by $64 \%$ and $12 \%$ compared to the cases with original homogeneous and averaged 
homogeneous cores respectively in the medium to long span cases. Based on this investigation, the core of sandwich panels are suggested to be manufactured as multi-layered foam rather than homogeneous foam. Furthermore, the correlation between the failure load and geometrical depth-span ratio is explored. In the long span cases e.g. geometrical ratio is or less than 0.3 , the predicted failure modes are dominated by sliding shear failure and the predicted failure loads are almost a constant, the number of layers of the core has effects in some extent on failure loads, and the case of the 8-layered core gives relatively higher failure load than others. In the medium span cases e.g. geometrical ratio is between 0.3 and 0.4 , mixed failure modes with through thickness shear and sliding shear failure are founded, and the failure loads are slightly decreased, and the number of layers of the core has the same influence as that in the long span cases. In the short span cases e.g. geometrical ratio is or bigger than 0.4 , failure modes are dominated by through thickness shear failure, and the failure loads are drastically increased, the influence of number of layers in the core are significant and varied in various number of layers in the core.

These findings can be used to carry out further researches and manufacture sandwich panels for various engineering applications with different geometrical depth-span ratios and variable layered sandwich cores. In most industrial applications, the long span FGSMLC panels would be usual cases. Considering the influence of the number of layers in the core of the FGSMLC, it is recommended to manufacture the FGSMLC using 3D printing technology in the future. The future work will also consider to investigate the failure mechanisms of the FGSMLC under different types of loading conditions such as impact, thermal or fatigue load using ECDM.

\section{References}

[1] Chandra N, Gopal KN, Raja S. Vibro-acoustic response of sandwich plates with functionally graded core. Acta Mechanica. 2017;228:2775-89.

[2] Antony Arul Prakash M, Jagannatha Guptha V, Sharma RS, Mohan B. Influence of cell size on the core shear properties of FRP honeycomb sandwich panels. Materials and Manufacturing Processes. 2012;27:169-76.

[3] Hassanpour Roudbeneh F, Liaghat G, Sabouri H, Hadavinia H. Experimental investigation of impact loading on honeycomb sandwich panels filled with foam. International Journal of Crashworthiness. 2018:1-12.

[4] Palanikumar K, Karunamoorthy L, Karthikeyan R. Multiple performance optimization of machining parameters on the machining of GFRP composites using carbide (K10) tool. Materials and Manufacturing Processes. 2006;21:846-52. 
[5] Xu G-d, Zhai J-j, Zeng T, Wang Z-h, Cheng S, Fang D-n. Response of composite sandwich beams with graded lattice core. Composite Structures. 2015;119:666-76.

[6] Rao S, Jayaraman K, Bhattacharyya D. Short fibre reinforced cores and their sandwich panels: Processing and evaluation. Composites Part A: Applied Science and Manufacturing. 2011;42:1236-46.

[7] Stocchi A, Colabella L, Cisilino A, Álvarez V. Manufacturing and testing of a sandwich panel honeycomb core reinforced with natural-fiber fabrics. Materials \& Design. 2014;55:394403.

[8] Vitale JP, Francucci G, Stocchi A. Thermal conductivity of sandwich panels made with synthetic and vegetable fiber vacuum-infused honeycomb cores. Journal of Sandwich Structures \& Materials. 2016;19:66-82.

[9] Shawkat W, Honickman H, Fam A. Investigation of a novel composite cladding wall panel in flexure. Journal of composite materials. 2008;42:315-30.

[10] Zoghi M. The international handbook of FRP composites in civil engineering: CRC Press, 2013.

[11] Tan K-T, Khan M. Impact and post-impact flexural behavior of composite sandwich structures in extreme low temperature arctic conditions. 12th International Conference on Sandwich Structures ICSS-12: Proceedings: EPFL-CCLab Composite Construction Laboratory; 2018. p. 89-91.

[12] Mao L, Guo R, Song Y, Chiang F-p. Full-field surface and interior deformation measurement of sandwich core material using digital speckle photography. 12th International Conference on Sandwich Structures ICSS-12: Proceedings: EPFL-CCLab Composite Construction Laboratory; 2018. p. 18-20.

[13] Correia J, Garrido M, Gonilha J, Branco F, Reis L. GFRP sandwich panels with PU foam and PP honeycomb cores for civil engineering structural applications: effects of introducing strengthening ribs. International Journal of Structural Integrity. 2012;3:127-47.

[14] Etemadi E, Khatibi AA, Takaffoli M. 3D finite element simulation of sandwich panels with a functionally graded core subjected to low velocity impact. Composite Structures. 2009;89:28-34.

[15] Udupa G, Rao SS, Gangadharan K. Functionally graded composite materials: an overview. Procedia Materials Science. 2014;5:1291-9.

[16] Akavci S. Mechanical behavior of functionally graded sandwich plates on elastic foundation. Composites Part B: Engineering. 2016;96:136-52.

[17] Apetre N, Sankar B, Ambur D. Low-velocity impact response of sandwich beams with functionally graded core. International Journal of Solids and Structures. 2006;43:2479-96.

[18] Capela C, Ferreira J, Costa J. Effect of the foam core density on the bending response on sandwich composites. Fibers and Polymers. 2013;14:597-602.

[19] Kashtalyan M, Menshykova M. Three-dimensional elasticity solution for sandwich panels with a functionally graded core. Composite structures. 2009;87:36-43.

[20] Icardi U, Ferrero L. Optimisation of sandwich panels with functionally graded core and faces. Composites Science and Technology. 2009;69:575-85. 
[21] Lashkari M, Rahmani O. Bending behavior of sandwich structures with flexible functionally graded core based on high-order sandwich panel theory. Meccanica. 2016;51:1093-112.

[22] Avila AF. Failure mode investigation of sandwich beams with functionally graded core. Composite Structures. 2007;81:323-30.

[23] Basaruddin K, Syayuthi A, Fartini M. Failure Behavior of Aircraft Sandwich Panels under Bending Load. Applied Mechanics \& Materials. 2015.

[24] Kelsey S, Gellatly R, Clark B. The shear modulus of foil honeycomb cores: A theoretical and experimental investigation on cores used in sandwich construction. Aircraft Engineering and Aerospace Technology. 1958;30:294-302.

[25] Wang L, Liu W, Fang H, Wan L. Behavior of sandwich wall panels with GFRP face sheets and a foam-GFRP web core loaded under four-point bending. Journal of composite materials. 2015;49:2765-78.

[26] Yan C, Song X, Zhu H, Jing C, Feng S. Flexural response of carbon fiber reinforced aluminum foam sandwich. Journal of composite materials. 2018;52:1887-97.

[27] Fang H, Shi H, Wang Y, Qi Y, Liu W. Experimental and theoretical study of sandwich panels with steel facesheets and GFRP core. Advances in Materials Science and Engineering. $2016 ; 2016$.

[28] Elices M, Guinea G, Gomez J, Planas J. The cohesive zone model: advantages, limitations and challenges. Engineering fracture mechanics. 2002;69:137-63.

[29] Blackman B, Hadavinia H, Kinloch AJ, Williams J. The use of a cohesive zone model to study the fracture of fibre composites and adhesively-bonded joints. International Journal of Fracture. 2003;119:25-46.

[30] Swati RF, Hua W, Elahi H, Khan A. Extended finite element method damage analysis of carbon fiber reinforced composites and crack propagation in mixed-mode using multiscale method and implementation of the method using ABAQUS extended finite element method damage analysis of carbon. 4th International conference on mechanics and mechatronics research, Xian IOP2017.

[31] Li X, Chen J. An extended cohesive damage model for simulating arbitrary damage propagation in engineering materials. Computer Methods in Applied Mechanics and Engineering. 2017; 315:744-59.

[32] Li X, Chen J. An extended cohesive damage model for simulating multicrack propagation in fibre composites. Composite Structures. 2016;143:1-8.

[33] Li X, Chen J. The implementation of the extended cohesive damage model for multicrack evolution in laminated composites. Composite Structures. 2016;139:68-76.

[34] Li X, Chen J. A highly efficient prediction of delamination migration in laminated composites using the extended cohesive damage model. Composite Structures. 2017;160:71221.

[35] Belytschko T, Black T. Elastic crack growth in finite elements with minimal remeshing. International journal for numerical methods in engineering. 1999;45:601-20.

[36] Reeder JR. 3D mixed-mode delamination fracture criteria-an experimentalist's perspective. Damage Compos. 2006:1-18. 
[37] Benzeggagh ML, Kenane M. Measurement of mixed-mode delamination fracture toughness of unidirectional glass/epoxy composites with mixed-mode bending apparatus. Composites Science and Technology. 1996;56:439-49. 